\title{
Surface Propensity of Aqueous Atmospheric Bromine at the Liquid- Gas Interface
}

\author{
Ivan Gladich,* Shuzhen Chen, Mario Vazdar, Anthony Boucly, Huanyu Yang, Markus Ammann,* \\ and Luca Artiglia*
}

Cite This: J. Phys. Chem. Lett. 2020, 11, 3422-3429

Read Online

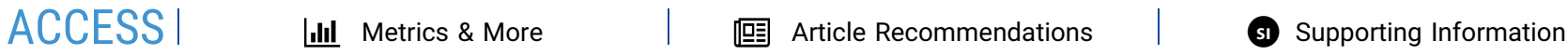

ABSTRACT: Multiphase reactions of halide ions in aqueous solutions exposed to the atmosphere initiate the formation of molecular halogen compounds in the gas phase. Their photolysis leads to halogen atoms, which are catalytic sinks for ozone, making these processes relevant for the regional and global tropospheric ozone budget. The affinity of halide ions in aqueous solution for the liquid-gas interface, which may influence their reactivity with gaseous species, has been debated. Our study focuses on the surface properties of the bromide ion and its oxidation products. In situ X-ray photoelectron spectroscopy carried out on a liquid jet combined with classical and first-principles molecular dynamics calculations was used to investigate the interfacial depth profile of bromide, hypobromite, hypobromous acid, and bromate. The simulated core electron binding energies support the experimentally observed values, which follow a correlation with bromine oxidation state for the anion series. Bromide ions are homogeneously distributed in the solution. Hypobromous acid, a key species in the multiphase cycling of bromine, is the only species showing surface propensity, which suggests a

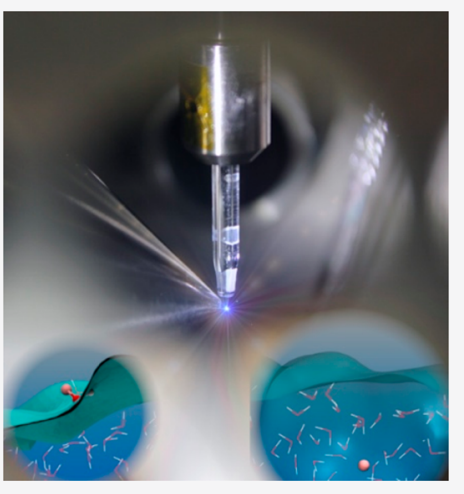
more important role of the interface in multiphase bromine chemistry than thought so far.

$\mathrm{D}$ iscovered in the 1980s, ozone depletion events in the lower levels of the polar atmosphere have been shown to correlate with a notable increment of bromine species contained in both gas and particle phases. ${ }^{1}$ Photolysis of molecular bromine and more generally halogen compounds leads to the corresponding halogen atoms, which are a catalytic sink for ozone. While the extent has been dramatic in the shallow polar marine boundary layer, ${ }^{2}$ it has meanwhile been recognized that processes leading to activation of halogens from their reservoirs, mostly halide ions in marine environments at all latitudes, have regional and global impacts on the oxidation capacity of the troposphere. ${ }^{3-9}$ Bromine activation is the result of a complex and multiphase (i.e., in the gas and/or at the interface of condensed water) reaction cycles. Oxidation of bromide may occur through various routes involving photolytically generated radicals, excited chromophoric organic matter, ${ }^{10}$ or ozone. In the latter case, acid-catalyzed oxidation of bromide leads to the formation of hypobromous acid $(\mathrm{HOBr}):^{3,11}$

$$
\begin{aligned}
& \mathrm{Br}_{(\mathrm{aq})}^{-}+\mathrm{O}_{3(\mathrm{~g})} \leftrightarrow\left[\mathrm{Br}^{\bullet} \mathrm{OOO}^{-}\right]_{(\mathrm{aq})} \\
& {\left[\mathrm{Br}^{\bullet} \mathrm{OOO}^{-}\right]_{(\mathrm{aq})}+\mathrm{H}_{(\mathrm{aq})}^{+} \leftrightarrow \mathrm{HOBr}_{(\mathrm{aq})}+\mathrm{O}_{2(\mathrm{~g})}} \\
& {\left[\mathrm{Br}^{\bullet} \mathrm{OOO}^{-}\right]_{(\mathrm{aq})}+\mathrm{H}_{2} \mathrm{O}_{(\mathrm{l})} \leftrightarrow \mathrm{HOBr}_{(\mathrm{aq})}+\mathrm{O}_{2(\mathrm{~g})}+\mathrm{OH}_{(\mathrm{aq})}^{-}}
\end{aligned}
$$

$\mathrm{HOBr}$ is also formed in the gas phase by the reaction of $\mathrm{BrO}$ radicals with $\mathrm{HO}_{2}$ radicals. Wherever it has been generated,
$\mathrm{HOBr}$ reacts with bromide in the aqueous phase, again in an acid-catalyzed reaction, which yields molecular $\mathrm{Br}_{2}$.

$$
\operatorname{HOBr}_{(\mathrm{aq})}+\mathrm{Br}_{(\mathrm{aq})}^{-}+\mathrm{H}_{(\mathrm{aq})}^{+} \leftrightarrow \mathrm{Br}_{2(\mathrm{~g})}+\mathrm{H}_{2} \mathrm{O}_{(\mathrm{l})}
$$

The overall efficiency of these complex multiphase reactions and cycles to affect the oxidation capacity depends greatly on the properties of the aqueous phases ( $\mathrm{pH}$ and other solutes) in seawater, salt pans, sea spray aerosol, sea ice, or snow and also on the oxidant levels in the gas and aqueous phases. ${ }^{12}$ The oxidation of bromide by ozone involves the formation of a precomplex, $\left[\mathrm{Br}^{\bullet} \mathrm{OOO}^{-}\right]$, also termed "ozonide", whose existence was postulated on the basis of kinetic mesurements ${ }^{11}$ and has been recently detected in situ at the liquid-gas interface by X-ray photoelectron spectroscopy (XPS). ${ }^{13}$ This ozonide is likely at the origin of the surface-enhanced bromide oxidation rates observed in many multiphase kinetic experiments. ${ }^{13,14}$ For the other bromide oxidation pathways and the reaction of $\mathrm{HOBr}$ with bromide, such surface enhancements have been discussed but not proven experimentally. , $^{\text {,15-17 }}$

Surface-enhanced reactions were thought to be driven by a surface propensity of the halide ions, an idea also supported by

Received: February 27, 2020

Accepted: April 13, 2020

Published: April 13, 2020 

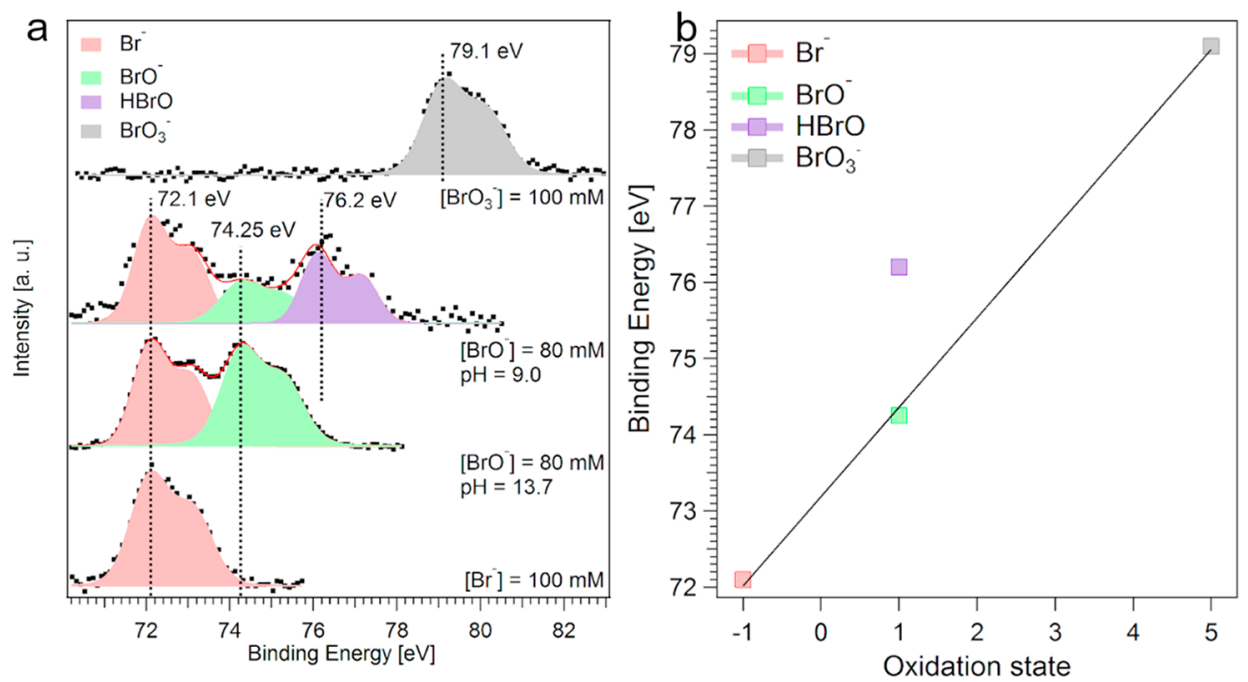

Figure 1. (a) XPS of the $\mathrm{Br} 3 \mathrm{~d}(h \nu=350 \mathrm{eV}$, corresponding to a kinetic energy of the Br $3 \mathrm{~d}$ peak of approximately $270 \mathrm{eV})$ core level peaks of four different bromine species. The plot also shows the deconvolution of the peaks and their assignments. (b) Plot of the binding energy shift observed experimentally with the corresponding oxidation state of bromine.

theoretical arguments that large polarizable anions are preferentially accommodated at the surface of water. ${ }^{18-20}$ Starting in 2000, the group of J. C. Hemminger has focused on the investigation, by means of ex situ and in situ XPS, of the deliquescence of halide salt crystals. ${ }^{21-23}$ The in situ XPS study of concentrated aqueous solutions generated from the controlled deliquescence of binary salts suggested the surface propensity of bromide ions. ${ }^{23}$ Other studies have suggested such behavior by means of surface sensitive experimental techniques like sum frequency generation spectroscopy and metastable impact electron spectroscopy ${ }^{24,25}$ in spite of the known increase in surface tension with halide salt concentration. In turn, Winter at al. characterized aqueous solutions containing iodide ions by means of in situ XPS on a liquid microjet. ${ }^{26}$ Although no depth profile analysis was reported, the data suggested that iodide shows a neutral behavior, i.e., neither surface enrichment nor surface depletion. The reason for the contrast to the earlier static saturated solution drop experiments is not entirely clear but may be related to contamination, beam damage (not an issue when using liquid jets), or the thermodynamic conditions. In 2009, the Winter group analyzed the surface properties of mixtures of chlorine species. $^{27}$ Combining XPS with molecular dynamics (MD) calculations, they demonstrated that $\mathrm{ClO}_{n}{ }^{-}$ions with higher values of $n$ (from 2 to 4 ) are more surface active whereas hypochlorite shows a slight surface depletion. ${ }^{27}$

Computer simulations have been used to support the experimental efforts, but the literature is still sparse due to the difficulties in treating highly polarizable species ${ }^{28-30}$ with different spin states between reactants and products. ${ }^{28}$ Electronic structure calculations have been performed in the gas phase to address the thermodynamics and kinetics of the reaction of bromide ions with ozone, ${ }^{28-30}$ reporting the reaction pathway for both spin surfaces. Lately, first-principles MD in combination with in situ XPS measurements has proven the stability of an ozonide complex at the water-gas interface. ${ }^{13}$ Classical MD simulations have shown bromide enhancement at the liquid interface ${ }^{19,20}$ and in mixtures of different sodium salts. ${ }^{31}$ Other MD and laboratory studies report surface segregation of halide ions on a growing ice crystal, populating the quasi-liquid layer in the ice-gas interface: ${ }^{32,33}$ this would suggest, in agreement with refs 21 and 22 , that the surface of seawater or sea ice is a possible source of bromine to fuel ozone depletion events. ${ }^{34}$ However, recent liquid jet XPS and theory results, as mentioned above, indicate a less pronounced surface enrichment of halide ions in aqueous solutions, ${ }^{35-38}$ questioning the amount of interfacial bromide to be immediately available for reactions with ozone or $\mathrm{HOBr}$ molecules colliding from the gas phase. Moreover, the acidity of the liquid-gas and ice-gas interfaces is still strongly debated, ${ }^{39-42}$ and the interfacial stability of some species, such as hypobromous acid, is unknown. Because ozone is poorly soluble in water, ${ }^{43}$ reaction 1 may proceed faster at the interface between the gas and condensed aqueous phase. If any of the follow-up species is also surface active, reactions 2-4 may occur via a surface specific route, as well.

In this work, we investigate the interfacial solvation of different bromine-based compounds involved in bromine activation and cycling at the liquid-gas interface using liquid jet XPS, electronic structure calculations, and MD simulations. XPS is a powerful method for assessing the structure of the liquid interface with high element selectivity and depth information limited to the first interfacial layers. ${ }^{44-46}$ Computer simulations provide an atomistic picture of the solvation environment at the liquid-gas interface and theoretical estimations of photoemission spectra. Our results have shown a molecular picture of the solvation of bromide in aqueous solution that differs from that suggested by polarizable $\mathrm{MD}^{19,20}$ or XPS experiments on static deliquesced crystals: ${ }^{21}$ neither surface enrichment nor depletion is observed for bromide or for hypobromite and bromate. Like other undissociated forms of acids, ${ }^{47}$ hypobromous acid shows a propensity for the liquid-gas interface.

Figure 1a shows the $\mathrm{Br} 3 \mathrm{~d}$ photoemission spectra of four aqueous solutions investigated in this study: $100 \mathrm{mM}$ bromide, $100 \mathrm{mM}$ bromate, and $80 \mathrm{mM}$ hypobromite at $\mathrm{pH} 13.7$ and 9.0. The $\mathrm{Br} 3 \mathrm{~d}$ spectrum of the $100 \mathrm{mM}$ bromide solution shows a peak that can be nicely fitted using a doublet, due to spin orbit splitting. The peak positions [binding energy (BE) of the $\mathrm{Br} 3 \mathrm{~d}_{5 / 2}$ peak of $72.1 \mathrm{eV}$ ] and the fitting parameters used are reported in Table 1 and are in good agreement with the photoemission data shown in ref 13 . The $\mathrm{Br} 3 \mathrm{~d}$ spectrum of 
Table 1. Fitting Parameters [binding energies, spin orbit splittings (SOS), and full widths at half-maximum (fwhm)] Used for the Deconvolutions of the $\mathrm{Br} 3 \mathrm{~d}$ Spectra

\begin{tabular}{llcc} 
& BE for $\mathrm{Br} 3 d_{5 / 2}(\mathrm{eV})$ & $\mathrm{SOS}(\mathrm{eV})$ & $\mathrm{fwhm}(\mathrm{eV})$ \\
$\mathrm{Br}^{-}$ & 72.1 & 1.00 & 0.96 \\
$\mathrm{BrO}^{-}$ & 74.25 & 1.05 & 1.15 \\
$\mathrm{HBrO}$ & 76.2 & 1.05 & 0.92 \\
$\mathrm{BrO}_{3}^{-}$ & 79.1 & 1.05 & 1.13 \\
\hline
\end{tabular}

the $80 \mathrm{mM}$ hypobromite solution at $\mathrm{pH} 13.7$ shows two peaks separated by approximately $2.1 \mathrm{eV}$, which can be fitted using two doublets whose $3 d_{5 / 2}$ peaks are found at 72.1 and 74.25 $\mathrm{eV}$. The former corresponds to bromide ions, whereas the latter to hypobromite ions (the preparation of the solutions is described in the Supporting Information). The $\mathrm{Br} 3 \mathrm{~d}$ spectrum of the hypobromite solution at $\mathrm{pH} 9$ shows a complex line shape, with two main features at approximately 72 and $76 \mathrm{eV}$. A deconvolution procedure clearly demonstrates that two doublets, centered at 72.1 and $76.2 \mathrm{eV}$, are not enough to obtain a good correlation with the raw experimental data; thus, a third doublet component, centered at 74.25 , is added. While the 72.1 and $74.25 \mathrm{eV}$ components are assigned to bromide and hypobromite ions, respectively, the $76.2 \mathrm{eV}$ peak can be assigned to hypobromous acid formed at $\mathrm{pH}$ 9. The last solution, $100 \mathrm{mM}$ bromate, shows a doublet whose $3 \mathrm{~d}_{5 / 2}$ peak centroid is at $79.1 \mathrm{eV}$. The $\mathrm{BEs}$ of the $\mathrm{Br} 3 \mathrm{~d}_{5 / 2}$ peaks of different species in Figure 1a are plotted as a function of the oxidation state of bromine in Figure $1 \mathrm{~b}$. The bromide, hypobromite, and bromate ions show a good linear correlation, which means that the positive chemical shift measured is proportional to the screening effects caused by the increase in the oxidation state from -1 to +5 . Interestingly, the dot corresponding to hypobromous acid lays outside. Because the oxidation state of bromine in hypobromite and in hypobromous acid is the same, the electronic state of bromine, and thus the core electron binding energy (CEBE), is influenced by the different protonation state.

Figure $2 \mathrm{a}$ shows the results of a depth profile of the $\mathrm{Br} 3 \mathrm{~d}$ photoemission signal of $100 \mathrm{mM}$ solutions of bromide and bromate ions. In this experiment, the $\mathrm{Br} 3 \mathrm{~d}$ signal was acquired at increasing excitation energies; thus, photoelectrons having increasing kinetic energies (KEs) were generated. Changing the KE allows the information depth of the analysis to be tuned, so that different thicknesses of the liquid filament (top axis of the graph) are probed. The areas of the $\mathrm{Br} 3 \mathrm{~d}$ spectra were normalized to the total cross section, to the photon flux, and to the mean escape depth [MED (see the Supporting Information)] of the photoelectrons calculated at each KE. Such a procedure allowed us to consider the effect of the anisotropy parameter at the measurement geometry used during the experiments (see the Supporting Information), which can affect the interpretation of the measured electron signal. ${ }^{48}$ In the case of the surface propensity (depletion) of a species, an increase (decrease) in the normalized area toward a low kinetic energy is expected. Although the signals oscillate around an average value of the area, our data do not show a clear trend, suggesting that bromide and bromate show neither surface enrichment nor surface depletion.

The series of $\mathrm{Br} 3 \mathrm{~d}$ spectra obtained from $80 \mathrm{mM}$ hypobromite solutions at $\mathrm{pH} 13.7$ and 9.0, acquired in the KE range of $150-770 \mathrm{eV}$, are shown in panels $\mathrm{a}$ and $\mathrm{b}$ of Figure S1, respectively. The peaks were deconvoluted using the
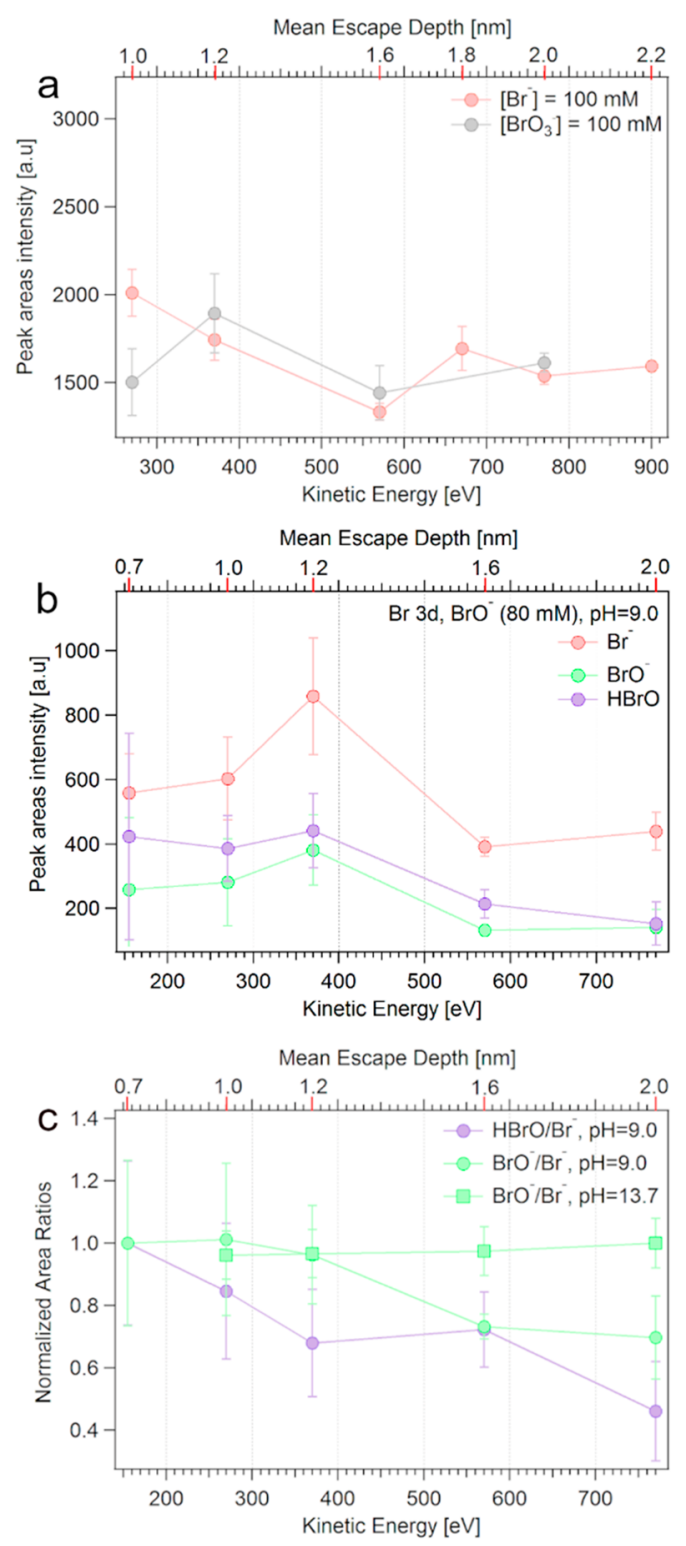

Figure 2. Normalized areas of the $\mathrm{Br} 3 \mathrm{~d}$ photoemission peaks acquired at increasing KEs of (a) $100 \mathrm{mM}$ bromide and $100 \mathrm{mM}$ bromate aqueous solutions and (b) an $80 \mathrm{mM}$ hypobromite aqueous solution. (c) Areas of the $\mathrm{Br} 3 \mathrm{~d}$ peaks of hypobromite and hypobromous acid normalized to the area of bromide in $80 \mathrm{mM}$ hypobromite aqueous solutions at $\mathrm{pH} 9.0$ and 13.7.

parameters listed in Table 1 . We focused the analysis on the hypobromite solution at $\mathrm{pH} 9.0$ (Figure $\mathrm{S} 1 \mathrm{~b}$ ), because it contains hypobromous acid, which is relevant in multiphase bromine chemistry. The areas of the species are displayed in Figure 2b. As already shown in Figure 2a, the area of the bromide component does not indicate an unambiguous behavior, i.e., neither surface propensity nor surface depletion. The behavior of the hypobromite component resembles that of bromide, whereas hypobromous acid shows a gradual decrease moving toward higher KEs. Because the bromide ions show a neutral behavior, we divided the areas of hypobromite and hypobromous acid by the area of bromide. The results, normalized to the maximum, are displayed in Figure $2 \mathrm{c}$. Hypobromous acid shows a 50\% decrease at the highest KE, and such a trend suggests a surface propensity. The hypobromite component also shows a decrease of approx- 
imately $25 \%$. Because hypobromite is the least intense component in the $\mathrm{Br} 3 \mathrm{~d}$ spectra acquired at $\mathrm{pH} 9.0$ (Figure $\mathrm{S} 1 \mathrm{~b})$, whereas its intensity is high at $\mathrm{pH} 13.7$, the $\mathrm{BrO}^{-} / \mathrm{Br}^{-}$ ratio was recalculated for the latter solution. The results are shown in Figure 2c (empty squares) and clearly display a neutral behavior, thus comparable to that of bromide. In addition, the line shapes of the $\mathrm{Br} 3 \mathrm{~d}$ spectra of the $\mathrm{pH} 9$ solution acquired at low KEs [150-370 eV (Figure S1b)] suggest the surface propensity of hypobromous acid. At $\mathrm{pH} 9$, with a $\mathrm{p} K_{\mathrm{a}}$ for hypobromous acid of 8.65 , the expected $\mathrm{HBrO}$ / $\mathrm{BrO}^{-}$ratio should be around 1 , whereas the intensity of the hypobromite component is much lower than that of hypobromous acid. At higher KEs $(550-770 \mathrm{eV})$, where the technique is more sensitive to the bulk, the ratio converges to 1. Such a behavior suggests the segregation of hypobromous acid in the first liquid layers.

Figure 3 shows the quantum mechanics/molecular mechanics ( $Q M / M M)$ free energy profile for the adsorption of

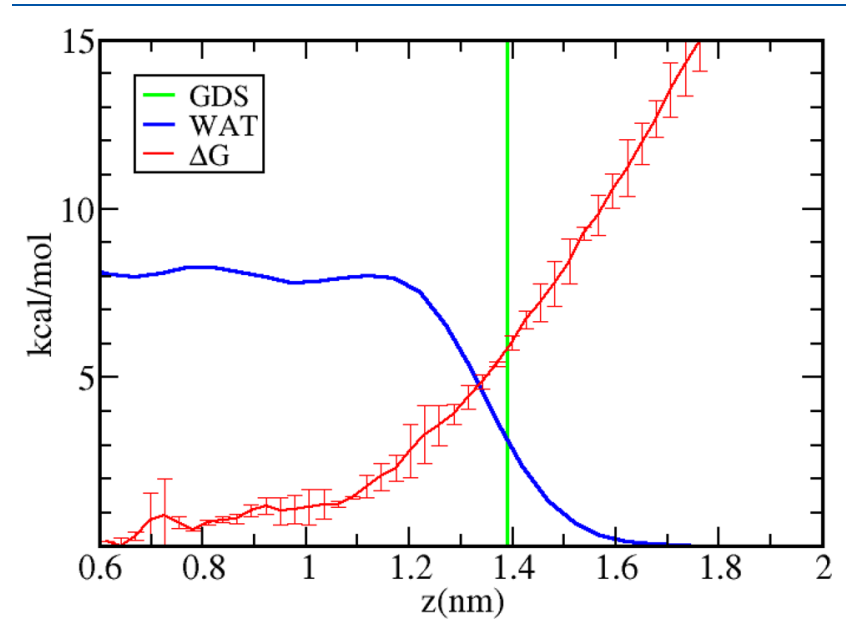

Figure 3. Quantum mechanics/molecular mechanics free energy profile (solid red line) for the adsorption for $\mathrm{Br}^{-}$on liquid water obtained. The blue line shows the water density (in arbitrary units). The vertical green line marks the Gibbs diving surface (GDS) for water $^{49}$ between the vapor and liquid water phases, defined as the surface of zero-solvent surface excess. ${ }^{49}$

bromide on liquid water. The red line is the free energy moving bromide from the gas $(z \sim 2 \mathrm{~nm})$ into the bulk water region $(z \sim 0.6 \mathrm{~nm})$. The results in Figure 3 were obtained by adaptively describing the solvation shell (consisting of $\sim 40$ water molecules) around bromide using a full QM approach while the rest of the system is treated at the MM level using the classical force field. This technique largely improves the characterization of the electrostatic and dispersion interactions, which is crucial to properly describe the interfacial behavior of heavy halide ions at the liquid-gas interface (see the Supporting Information for details). Figure 3 shows no evidence of the interfacial minimum for the free energy in the proximity of the GDS, which indicates the absence of surface enhancement of bromide at the liquid-gas interface. This is in agreement with the results recently proposed by Horinek et al. ${ }^{38}$ using a nonpolarizable force field optimized to reproduce bulk thermodynamic properties as well as photoelectron spectroscopy measurements. ${ }^{35,38}$ Our results are also in line with those of recent first-principles $\mathrm{MD}$ of iodide adsorption at the air-liquid water interface ${ }^{36}$ and indicate a surface propensity for heavy halide ions much lower than those predicted by previous MD based on the classical polarizable force field. ${ }^{18,20,50}$ A closer look at the free energy profile of Figure 3 and Figure S2 shows that a small depletion of bromide would be expected in the first 1-2 $\AA$ of the liquid interface, before the concentration value converges to the bulk one. Such a small surface depletion is not confirmed by the experimental data (Figure 2a,b) due to the larger probed depth even under the most surface sensitive conditions (photoelectron kinetic energy of $155 \mathrm{eV}$, corresponding to a $7 \AA$ MED).

Figure 4 displays the probability distribution, obtained by classical MD simulations, for hypobromous acid, its conjugate base, and bromate ions across a liquid water slab with two liquid-gas interfaces. In the case of hypobromite and bromate ions, we adopted a scaled charge approach, which is a convenient way to include induced polarizability in nonpolarizable $\mathrm{MD}$ of charged ions in solution. It is known that such an approach overestimates the surface propensity of ionic species at the liquid-gas interface. ${ }^{52}$ Despite that, panels a and b of Figure 4 clearly show a neutral/slightly bulk preference for both ions. Such a depletion extends to a few angstroms of the liquid (1-2 $\AA$ ); thus, in situ photoemission cannot detect it even under the most surface sensitive conditions and thus shows an overall neutral behavior of the depth profiles (Figure $2 a, b)$. On the other hand, Figure $4 c$ reports a surface enhancement for hypobromous acid, clearly marked by the two strong peaks in the density profile at the interfacial regions. Solute surface excesses from the GDS of water are reported in Table 2. Positive (negative) values of surface excess provide quantitative evidence for the interfacial (bulk) solvation preference observed in Figures 3 and 4. The reason behind the surface enrichment of hypobromous acid is the stability of the undissociated form of acids at the liquid-gas interface. ${ }^{47}$ Figure $4 \mathrm{~d}$ provides more molecular details about the interfacial solvation of hypobromous acid at the water surface, which is also supported by the average number of water oxygens within the first solvation shell extracted from the classical MD trajectory (Table S2). The inset shows the probability distribution of the distance from each atom constituting hypobromous acid to the instantaneous interface: ${ }^{51}$ the proton mainly resides at the interface (peak at zero), while the oxygen and bromine atoms are exposed to the gas phase (in the inset, peaks in the positive range), further supporting the molecular picture of the interfacial solvation of hypobromous acid.

Table 3 reports the calculated CEBEs at the MP2 level of theory and their comparison with the experimental values obtained by XPS (Figure 1 and Table 1). The top part of Table 3 contains the CEBEs in the gas phase. $\Delta$, which is the chemical shift between the CEBE of the considered compound and the CEBE of bromide, shows significant differences compared to the same BE shift observed experimentally, $\Delta_{\text {exp }}$. As already observed in ref 13 , such a difference is due to the need to consider the solvation shell of the species. The second part of Table 3 reports the CEBEs of the species in 5 and 10 water clusters, extracted from snapshots of the MD trajectories. Table S1 contains the CEBEs in 7 water clusters. The third column of Table 3 shows the percentage variation of the CEBE in water with respect to the value calculated for the same species in the gas phase, $\delta_{\mathrm{CEBE}}(\%)$. While the $\delta_{\mathrm{CEBE}}$ values of bromide, hypobromite, and bromate significantly change upon addition of water (from $5.9 \%$ to $7.5 \%$ ), a slight variation is observed for hypobromous acid $(-0.3 \%$ and $-0.9 \%$ with 5 and 10 waters, respectively). As shown in panels $\mathrm{c}$ and $\mathrm{d}$ of Figure 


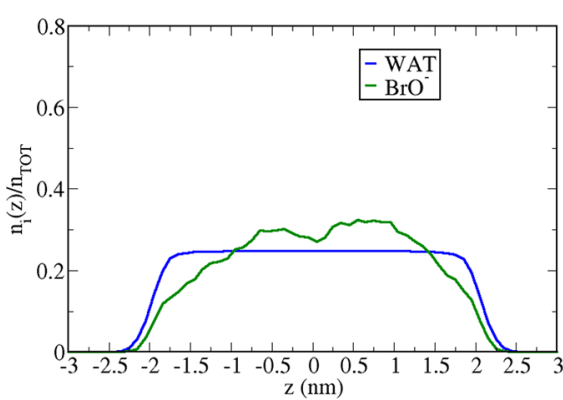

(a)

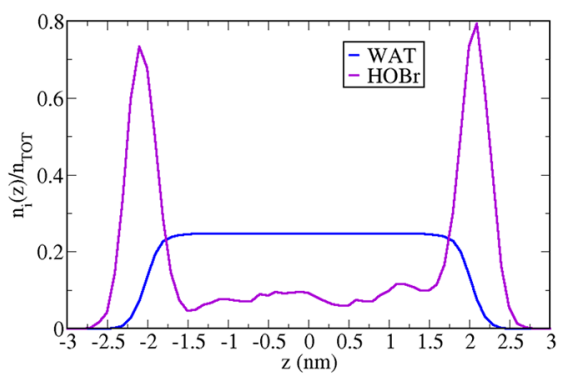

(c)

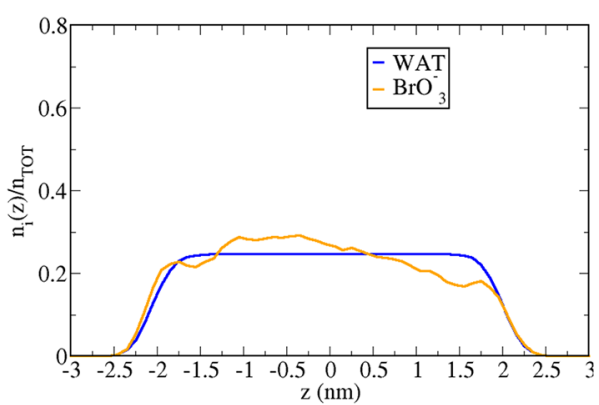

(b)

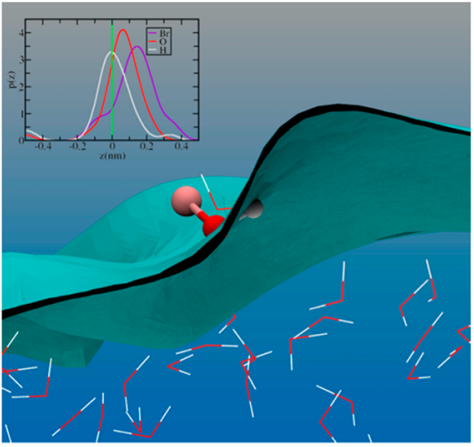

(d)

Figure 4. Probability density profile, $n_{\mathrm{i}} / n_{\mathrm{TOT}}$, normalized to unity as a function of the $z$-coordinate perpendicular to the liquid water-gas interface for (a) $\mathrm{BrO}^{-}$, (b) $\mathrm{BrO}_{3}^{-}$, and (c) $\mathrm{HOBr}$. The water profile is colored blue. All profiles were normalized to unity. (d) Snapshot of the $\mathrm{HOBr}$ molecule at the liquid-gas interface. The inset shows the probability distribution for the location of each atom of $\mathrm{HBrO}$ at the liquid-gas interface defined as the Willard-Chandler (WC) dividing surface. ${ }^{51}$

Table 2. Solute Surface Excesses $(\Gamma$, number per square nanometer) Calculated from the Density and Free Energy Profiles in Figures 3 and 4, Respectively ${ }^{a}$

$\begin{array}{ccccc} & \mathrm{Br}^{-} & \mathrm{BrO}^{-} & \mathrm{BrO}_{3}^{-} & \mathrm{HOBr} \\ \Gamma & -0.09 & -0.05 & 0.02 & 0.35\end{array}$

${ }^{a_{T}}$ The surface excess has been calculated at the Gibbs diving surface (GDS) using the approach described in refs 49,52 , and 53.

4, hypobromous acid is desolvated at the interface and fewer water molecules are required to cause convergence of the CEBE. Hypobromite and bromide are (almost) fully solvated, and thus, more water molecules are needed to obtain a more complete solvation shell and stable CEBE values. Variations among the CEBEs using clusters of different sizes are within the statistical error bar, indicating that water clusters containing 5-10 water molecules are sufficient to reach a reasonable description of the solvation environment for the species, as also shown by the average number of water oxygens within the first solvation shell (Table S2). In the case of bromate, due to the larger size of the molecule, clusters containing 10 water molecules could still not be enough to cause convergence of the CEBE: this explains the largest deviation between the calculated $\Delta$ and the experimental $\Delta_{\text {exp }}$. CEBE calculations for larger clusters are, however, extremely challenging because of their computational cost. Table 3 shows that experimental and computed shifts agree on the relative position of the CEBEs (i.e., $\mathrm{Br}^{-}<\mathrm{BrO}^{-}<\mathrm{HOBr}<\mathrm{BrO}_{3}^{-}$) even if for hypobromous acid and bromate the computed shifts are approximately $2 \mathrm{eV}$ larger than those observed with XPS. However, considering the error bar in the CEBE evaluation
Table 3. Core Electron Binding Energies (CEBE) for $\mathrm{Br}^{-}$, $\mathrm{BrO}^{-}, \mathrm{HOBr}$, and $\mathrm{BrO}_{3}^{-}$at the $\mathrm{MP2} / \mathrm{cc}-\mathrm{pVTZ}$ Level of Theory in the Gas Phase and in a Cluster Containing 5 and 10 Molecules of Water ${ }^{a}$

\begin{tabular}{|c|c|c|c|c|}
\hline & $\begin{array}{c}\operatorname{CEBE}\left(\mathrm{Br}^{-}{ }_{3 \mathrm{~d}}\right) \\
(\mathrm{eV})\end{array}$ & $\begin{array}{l}\delta_{\text {CEBE }} \text { (gas } \\
\text { phase-water } \\
\text { cluster) }(\%)\end{array}$ & $\begin{array}{c}\Delta(\mathrm{CEBE}- \\
\left.\text { CEBE }_{\mathrm{Br}}{ }^{-}\right) \\
(\mathrm{eV})\end{array}$ & $\begin{array}{c}\Delta_{\text {exp }}(C E B E- \\
\left.\text { CEBE } E_{\mathrm{Br}}^{-}\right) \\
(\mathrm{eV})^{-}\end{array}$ \\
\hline \multicolumn{5}{|c|}{ MP2/cc-pVTZ, Gas Phase } \\
\hline${ }^{1} \mathrm{Br}^{-}$ & 70.01 & - & 0.00 & 0.00 \\
\hline${ }^{1} \mathrm{BrO}^{-}$ & 73.10 & - & 3.09 & 2.15 \\
\hline${ }^{1} \mathrm{HOBr}$ & 82.38 & - & 12.64 & 4.1 \\
\hline${ }^{1} \mathrm{BrO}_{3}^{-}$ & 81.25 & - & 11.24 & 7 \\
\hline \multicolumn{5}{|c|}{ MP2/cc-pVTZ, 5-Water Cluster } \\
\hline${ }^{1} \mathrm{Br}^{-}$ & $74.74 \pm 0.87$ & $6.7 \pm 1.2$ & $0.00 \pm 1.23$ & 0.00 \\
\hline${ }^{1} \mathrm{BrO}^{-}$ & $77.41 \pm 0.49$ & $5.9 \pm 0.7$ & $2.67 \pm 1.00$ & 2.15 \\
\hline${ }^{1} \mathrm{HOBr}$ & $82.10 \pm 0.39$ & $-0.3 \pm 0.5$ & $7.36 \pm 0.95$ & 4.1 \\
\hline${ }^{1} \mathrm{BrO}_{3}^{-}$ & $86.59 \pm 2.06$ & $6.2 \pm 2.2$ & $11.85 \pm 2.24$ & 7 \\
\hline \multicolumn{5}{|c|}{ MP2/cc-pVTZ, 10-Water Cluster } \\
\hline${ }^{1} \mathrm{Br}^{-}$ & $75.25 \pm 0.28$ & $7.5 \pm 0.4$ & $0.00 \pm 0.40$ & 0.00 \\
\hline${ }^{1} \mathrm{BrO}^{-}$ & $77.49 \pm 0.59$ & $6.0 \pm 0.8$ & $2.24 \pm 0.65$ & 2.15 \\
\hline${ }^{1} \mathrm{HOBr}$ & $81.61 \pm 0.40$ & $-0.9 \pm 0.5$ & $6.36 \pm 0.49$ & 4.1 \\
\hline${ }^{1} \mathrm{BrO}_{3}^{-}$ & $85.71 \pm 0.99$ & $5.2 \pm 1.1$ & $10.46 \pm 1.02$ & 7 \\
\hline
\end{tabular}

${ }^{a} \mathrm{CEBE}$ values are calculated as an average over several snapshots taken from the MD trajectory (see the Supporting Information). $\delta_{\mathrm{CEBE}}$ is the percent change in the CEBE (with respect to the gas phase value) upon addition of 5 and 10 water molecules. $\Delta$ and $\Delta_{\exp }$ are the calculated and experimental CEBE differences with respect to the $\mathrm{Br}^{-}$value, respectively. Gas phase values for $\mathrm{Br}^{-}$and $\mathrm{BrO}^{-}$were taken from ref 13 . 
and the broad peaks in the XPS, the confidence levels of the computed and experimental CEBEs pretty much overlap.

To summarize, we determined the solvation environment of different bromine species at the liquid-gas interface by combining depth profile measurements from liquid jet XPS, electronic structure calculations, and classical/first-principles MD simulations. Our results suggest that bromide does not display a net surface preference, in good agreement with the results of in situ XPS performed on a liquid filament containing iodide ions ${ }^{26}$ and recent MD simulations. ${ }^{38}$ As mentioned in the introduction, previous literature reports demonstrated the surface propensity of bromide ions in deliquesced salt surfaces. $^{23-25}$ However, such measurements were performed on a deliquesced salt, thus under static conditions allowing more pronounced beam damage effects. Such effects are limited in a liquid jet experiment, because the purity and concentration of the solutions can be controlled and because beam-induced effects are negligible due to the permanently renewed liquid surface. Like bromide, hypobromite and bromate do not display a net interfacial/bulk surface preference. Our findings also indicate that hypobromous acid shows a clear surface propensity as proven by the BE shift compared to the conjugate base, depth profile measurements, and MD simulations.

Our results have important implications for the multiphase chemistry of bromine species, including reactions $1-4$, in the atmosphere. Moreover, the findings of this work also clarify the solvation environment of chemical players involved in multiphase bromine chemistry, which are also relevant in the debromination chemistry of wastewater. ${ }^{54}$ Our recent work has demonstrated that the ozonide formed in reaction 1 , the $\left[\mathrm{Br}^{\bullet} \mathrm{OOO}^{-}\right]$precomplex, has a high propensity for the liquidgas interface, ${ }^{13}$ which is the main reason for the oxidation of bromide by ozone proceeding more efficiently at the surface than in the bulk liquid and not any enhancement of bromide itself at the interface suggested previously. ${ }^{23}$ This is now confirmed by our study demonstrating the absence of enhancement for bromide. Second, $\mathrm{HOBr}$ (hypobromous acid), formed by either reactions 2 and 3 or photochemical cycles in the gas phase, exhibits significant surface enrichment. This opens up the possibility of a surface specific reaction route for reaction 4. Kinetic experiments available so far are not conclusive in that regard ${ }^{14,17,34,55,56}$ and must continue to be performed.

\section{ASSOCIATED CONTENT}

\section{SI Supporting Information}

The Supporting Information is available free of charge at https://pubs.acs.org/doi/10.1021/acs.jpclett.0c00633.

Details of the experimental methods, including preparation of the aqueous solutions and description of the liquid jet apparatus and methods; photoemission spectra (depth profile) of the hypobromite solutions at different $\mathrm{pH}$ values; details of computational methods, including $\mathrm{QM} / \mathrm{MM}$ and the umbrella sampling setup; force field and integration parameters for classical molecular dynamics; and electronic structure method and calculation procedure for core electron binding energies (PDF)

\section{AUTHOR INFORMATION}

\section{Corresponding Authors}

Ivan Gladich - Qatar Environment \& Energy Research Institute, Hamad Bin Khalifa University, Doha, Qatar; (1) orcid.org/ 0000-0003-0929-3439; Email: igladich@hbku.edu.qa

Markus Ammann - Laboratory of Environmental Chemistry, Paul Scherrer Institut, 5232 Villigen, Switzerland; 이이.org/ 0000-0001-5922-9000; Email: markus.ammann@psi.ch

Luca Artiglia - Laboratory of Environmental Chemistry and Laboratory for Sustainable Chemistry and Catalysis, Paul Scherrer Institut, 5232 Villigen, Switzerland; 다이.org/ 0000-0003-4683-6447; Email: luca.artiglia@psi.ch

\section{Authors}

Shuzhen Chen - Laboratory of Environmental Chemistry, Paul Scherrer Institut, 5232 Villigen, Switzerland; Institute of Atmospheric and Climate Sciences, ETH Zurich, 8092 Zurich, Switzerland

Mario Vazdar - Division of Organic Chemistry and Biochemistry, Rudjer Boškovic Institute, 10000 Zagreb, Croatia; O orcid.org/0000-0001-6905-6174

Anthony Boucly - Laboratory of Environmental Chemistry, Paul Scherrer Institut, 5232 Villigen, Switzerland

Huanyu Yang - Laboratory of Environmental Chemistry, Paul Scherrer Institut, 5232 Villigen, Switzerland; Institute of Atmospheric and Climate Sciences, ETH Zurich, 8092 Zurich, Switzerland

Complete contact information is available at:

https://pubs.acs.org/10.1021/acs.jpclett.0c00633

\section{Notes}

The authors declare no competing financial interest.

\section{ACKNOWLEDGMENTS}

For high-performance computer resources and services, the authors acknowledge the Research Computing Group at Texas A\&M University at Qatar and a grant from the Computational Materials and Processes Center of the Qatar Environment and Energy Research Institute (CMP-QEERI) under Project ID HPC-P19004. I.G. acknowledges Dr. Marcelo A. Carignano for fruitful discussions. S.C. and M.A. appreciate the financial support from the Swiss National Science Foundation (Grant 169176).

\section{REFERENCES}

(1) Barrie, L. A.; Bottenheim, J. W.; Schnell, R. C.; Crutzen, P. J.; Rasmussen, R. A. Ozone destruction and photochemical reactions at polar sunrise in the lower Arctic atmosphere. Nature 1988, 334 (6178), 138-141.

(2) Domine, F.; Shepson, P. B. Air-snow interactions and atmospheric chemistry. Science 2002, 297 (5586), 1506-1510.

(3) Simpson, W. R.; von Glasow, R.; Riedel, K.; Anderson, P.; Ariya, P.; Bottenheim, J.; Burrows, J.; Carpenter, L. J.; Frieß, U.; Goodsite, M. E.; Heard, D.; Hutterli, M.; Jacobi, H. W.; Kaleschke, L.; Neff, B.; Plane, J.; Platt, U.; Richter, A.; Roscoe, H.; Sander, R.; Shepson, P.; Sodeau, J.; Steffen, A.; Wagner, T.; Wolff, E. Halogens and their role in polar boundary-layer ozone depletion. Atmos. Chem. Phys. 2007, 7 (16), 4375-4418.

(4) Abbatt, J. P. D.; Thomas, J. L.; Abrahamsson, K.; Boxe, C.; Granfors, A.; Jones, A. E.; King, M. D.; Saiz-Lopez, A.; Shepson, P. B.; Sodeau, J.; Toohey, D. W.; Toubin, C.; von Glasow, R.; Wren, S. N.; Yang, X. Halogen activation via interactions with environmental ice and snow in the polar lower troposphere and other regions. Atmos. Chem. Phys. 2012, 12 (14), 6237-6271. 
(5) Simpson, W. R.; Brown, S. S.; Saiz-Lopez, A.; Thornton, J. A.; von Glasow, R. Tropospheric Halogen Chemistry: Sources, Cycling, and Impacts. Chem. Rev. 2015, 115 (10), 4035-4062.

(6) Schmidt, J. A.; Jacob, D. J.; Horowitz, H. M.; Hu, L.; Sherwen, T.; Evans, M. J.; Liang, Q.; Suleiman, R. M.; Oram, D. E.; Le Breton, M.; Percival, C. J.; Wang, S.; Dix, B.; Volkamer, R. Modeling the observed tropospheric $\mathrm{BrO}$ background: Importance of multiphase chemistry and implications for ozone, $\mathrm{OH}$, and mercury. J. Geophys. Res.: Atmos. 2016, 121 (19), 11819-11835.

(7) Sherwen, T.; Schmidt, J. A.; Evans, M. J.; Carpenter, L. J.; Großmann, K.; Eastham, S. D.; Jacob, D. J.; Dix, B.; Koenig, T. K.; Sinreich, R.; Ortega, I.; Volkamer, R.; Saiz-Lopez, A.; Prados-Roman, C.; Mahajan, A. S.; Ordóñez, C. Global impacts of tropospheric halogens $(\mathrm{Cl}, \mathrm{Br}, \mathrm{I})$ on oxidants and composition in GEOS-Chem. Atmos. Chem. Phys. 2016, 16 (18), 12239-12271.

(8) Sherwen, T.; Evans, M. J.; Carpenter, L. J.; Schmidt, J. A.; Mickley, L. J. Halogen chemistry reduces tropospheric O3 radiative forcing. Atmos. Chem. Phys. 2017, 17 (2), 1557-1569.

(9) Pratt, K. A.; Custard, K. D.; Shepson, P. B.; Douglas, T. A.; Pöhler, D.; General, S.; Zielcke, J.; Simpson, W. R.; Platt, U.; Tanner, D. J.; Gregory Huey, L.; Carlsen, M.; Stirm, B. H. Photochemical production of molecular bromine in Arctic surface snowpacks. Nat. Geosci. 2013, 6 (5), 351-356.

(10) Corral Arroyo, P.; Aellig, R.; Alpert, P. A.; Volkamer, R.; Ammann, M. Halogen activation and radical cycling initiated by imidazole-2-carboxaldehyde photochemistry. Atmos. Chem. Phys. 2019, 19 (16), 10817-10828.

(11) Liu, Q.; Schurter, L. M.; Muller, C. E.; Aloisio, S.; Francisco, J. S.; Margerum, D. W. Kinetics and Mechanisms of Aqueous Ozone Reactions with Bromide, Sulfite, Hydrogen Sulfite, Iodide, and Nitrite Ions. Inorg. Chem. 2001, 40 (17), 4436-4442.

(12) Wren, S. N.; Donaldson, D. J. How does deposition of gas phase species affect $\mathrm{pH}$ at frozen salty interfaces? Atmos. Chem. Phys. 2012, 12 (21), 10065-10073.

(13) Artiglia, L.; Edebeli, J.; Orlando, F.; Chen, S.; Lee, M.-T.; Corral Arroyo, P.; Gilgen, A.; Bartels-Rausch, T.; Kleibert, A.; Vazdar, M.; Andres Carignano, M.; Francisco, J. S.; Shepson, P. B.; Gladich, I.; Ammann, M. A surface-stabilized ozonide triggers bromide oxidation at the aqueous solution-vapour interface. Nat. Commun. 2017, 8 (1), 700 .

(14) Oldridge, N. W.; Abbatt, J. P. D. Formation of Gas-Phase Bromine from Interaction of Ozone with Frozen and Liquid $\mathrm{NaCl}$ / $\mathrm{NaBr}$ Solutions: Quantitative Separation of Surficial Chemistry from Bulk-Phase Reaction. J. Phys. Chem. A 2011, 115 (12), 2590-2598.

(15) Wang, S.; McNamara, S. M.; Moore, C. W.; Obrist, D.; Steffen, A.; Shepson, P. B.; Staebler, R. M.; Raso, A. R. W.; Pratt, K. A. Direct detection of atmospheric atomic bromine leading to mercury and ozone depletion. Proc. Natl. Acad. Sci. U. S. A. 2019, 116 (29), 14479.

(16) Peterson, P. K.; Pöhler, D.; Sihler, H.; Zielcke, J.; General, S.; Frieß, U.; Platt, U.; Simpson, W. R.; Nghiem, S. V.; Shepson, P. B.; Stirm, B. H.; Dhaniyala, S.; Wagner, T.; Caulton, D. R.; Fuentes, J. D.; Pratt, K. A. Observations of bromine monoxide transport in the Arctic sustained on aerosol particles. Atmos. Chem. Phys. 2017, 17 (12), $7567-7579$.

(17) Ammann, M.; Cox, R. A.; Crowley, J. N.; Jenkin, M. E.; Mellouki, A.; Rossi, M. J.; Troe, J.; Wallington, T. J. Evaluated kinetic and photochemical data for atmospheric chemistry: Volume VI heterogeneous reactions with liquid substrates. Atmos. Chem. Phys. 2013, 13 (16), 8045-8228.

(18) Jungwirth, P.; Tobias, D. J. Molecular structure of salt solutions: A new view of the interface with implications for heterogeneous atmospheric chemistry. J. Phys. Chem. B 2001, 105 (43), 10468-10472.

(19) Jungwirth, P.; Tobias, D. J. Ions at the air/water interface. J. Phys. Chem. B 2002, 106 (25), 6361-6373.

(20) Tobias, D. J.; Stern, A. C.; Baer, M. D.; Levin, Y.; Mundy, C. J. Simulation and Theory of Ions at Atmospherically Relevant Aqueous Liquid-Air Interfaces. Annu. Rev. Phys. Chem. 2013, 64 (1), 339-359.
(21) Ghosal, S.; Shbeeb, A.; Hemminger, J. C. Surface segregation of bromine in bromide doped $\mathrm{NaCl}$ : Implications for the seasonal variations in Arctic ozone. Geophys. Res. Lett. 2000, 27 (13), 18791882.

(22) Ghosal, S.; Brown, M. A.; Bluhm, H.; Krisch, M. J.; Salmeron, M.; Jungwirth, P.; Hemminger, J. C. Ion Partitioning at the Liquid/ Vapor Interface of a Multicomponent Alkali Halide Solution: A Model for Aqueous Sea Salt Aerosols. J. Phys. Chem. A 2008, 112 (48), 12378-12384.

(23) Ghosal, S.; Hemminger, J. C.; Bluhm, H.; Mun, B. S.; Hebenstreit, E. L. D.; Ketteler, G.; Ogletree, D. F.; Requejo, F. G.; Salmeron, M. Electron Spectroscopy of Aqueous Solution Interfaces Reveals Surface Enhancement of Halides. Science 2005, 307 (5709), 563.

(24) Schnitzer, C.; Baldelli, S.; Shultz, M. J. Sum Frequency Generation of Water on $\mathrm{NaCl}, \mathrm{NaNO} 3, \mathrm{KHSO} 4, \mathrm{HCl}, \mathrm{HNO} 3$, and H2SO4 Aqueous Solutions. J. Phys. Chem. B 2000, 104 (3), 585-590.

(25) Höfft, O.; Borodin, A.; Kahnert, U.; Kempter, V.; Dang, L. X.; Jungwirth, P. Surface Segregation of Dissolved Salt Ions. J. Phys. Chem. B 2006, 110 (24), 11971-11976.

(26) Weber, R.; Winter, B.; Schmidt, P. M.; Widdra, W.; Hertel, I. V.; Dittmar, M.; Faubel, M. Photoemission from Aqueous AlkaliMetal-Iodide Salt Solutions Using EUV Synchrotron Radiation. J. Phys. Chem. B 2004, 108 (15), 4729-4736.

(27) Ottosson, N.; Vácha, R.; Aziz, E. F.; Pokapanich, W.; Eberhardt, W.; Svensson, S.; Öhrwall, G.; Jungwirth, P.; Björneholm, O.; Winter, B. Large variations in the propensity of aqueous oxychlorine anions for the solution/vapor interface. J. Chem. Phys. 2009, 131 (12), 124706.

(28) Gladich, I.; Francisco, J. S.; Buszek, R. J.; Vazdar, M.; Carignano, M. a.; Shepson, P. B. Ab Initio Study of the Reaction of Ozone with Bromide Ion. J. Phys. Chem. A 2015, 119, 4482.

(29) Rayne, S.; Forest, K. A G4MP2 and G4 theoretical study on reactions occurring during the ozonation of bromide containing waters. Comput. Theor. Chem. 2014, 1031, 22-33.

(30) Trogolo, D.; Arey, J. S.; Tentscher, P. R. Gas-Phase Ozone Reactions with a Structurally Diverse Set of Molecules: Barrier Heights and Reaction Energies Evaluated by Coupled Cluster and Density Functional Theory Calculations. J. Phys. Chem. A 2019, 123 (2), 517-536.

(31) Gladich, I.; Shepson, P. B.; Carignano, M. A.; Szleifer, I. Halide Affinity for the Water-Air Interface in Aqueous Solutions of Mixtures of Sodium Salts. J. Phys. Chem. A 2011, 115 (23), 5895-5899.

(32) Cho, H.; Shepson, P. B.; Barrie, L. A.; Cowin, J. P.; Zaveri, R. NMR investigation of the quasi-brine layer in ice/brine mixtures. $J$. Phys. Chem. B 2002, 106 (43), 11226-11232.

(33) Carignano, M. A.; Shepson, P. B.; Szleifer, I. Ions at the ice/ vapor interface. Chem. Phys. Lett. 2007, 436 (1-3), 99-103.

(34) Hunt, S. W.; Roeselová, M.; Wang, W.; Wingen, L. M.; Knipping, E. M.; Tobias, D. J.; Dabdub, D.; Finlayson-Pitts, B. J. Formation of Molecular Bromine from the Reaction of Ozone with Deliquesced $\mathrm{NaBr}$ Aerosol: Evidence for Interface Chemistry. J. Phys. Chem. A 2004, 108 (52), 11559-11572.

(35) Olivieri, G.; Parry, K. M.; D’Auria, R.; Tobias, D. J.; Brown, M. A. Specific Anion Effects on $\mathrm{Na}+$ Adsorption at the Aqueous Solution-Air Interface: MD Simulations, SESSA Calculations, and Photoelectron Spectroscopy Experiments. J. Phys. Chem. B 2018, 122 (2), 910-918.

(36) Baer, M. D.; Mundy, C. J. Toward an understanding of the specific ion effect using density functional theory. J. Phys. Chem. Lett. 2011, 2, 1088-1093.

(37) Olivieri, G.; Parry, K. M.; Powell, C. J.; Tobias, D. J.; Brown, M. A. Quantitative interpretation of molecular dynamics simulations for $\mathrm{X}$-ray photoelectron spectroscopy of aqueous solutions. J. Chem. Phys. 2016, 144 (15), 154704-154704.

(38) Horinek, D.; Herz, A.; Vrbka, L.; Sedlmeier, F.; Mamatkulov, S. I.; Netz, R. R. Specific ion adsorption at the air/water interface: The role of hydrophobic solvation. Chem. Phys. Lett. 2009, 479 (4), 173183. 
(39) Beattie, J. K.; Djerdjev, A. M.; Warr, G. G. The surface of neat water is basic. Faraday Discuss. 2009, 141 (0), 31-39.

(40) Buch, V.; Milet, A.; Vácha, R.; Jungwirth, P.; Devlin, J. P. Water surface is acidic. Proc. Natl. Acad. Sci. U. S. A. 2007, 104 (18), 7342.

(41) Tse, Y.-L. S.; Chen, C.; Lindberg, G. E.; Kumar, R.; Voth, G. A. Propensity of Hydrated Excess Protons and Hydroxide Anions for the Air-Water Interface. J. Am. Chem. Soc. 2015, 137 (39), 12610-12616.

(42) Agmon, N.; Bakker, H. J.; Campen, R. K.; Henchman, R. H.; Pohl, P.; Roke, S.; Thämer, M.; Hassanali, A. Protons and Hydroxide Ions in Aqueous Systems. Chem. Rev. 2016, 116 (13), 7642-7672.

(43) Chameides, W. L.; Davis, D. D. The free radical chemistry of cloud droplets and its impact upon the composition of rain. J. Geophys. Res. 1982, 87 (C7), 4863-4877.

(44) Winter, B.; Faubel, M. Photoemission from Liquid Aqueous Solutions. Chem. Rev. 2006, 106 (4), 1176-1211.

(45) Seidel, R.; Thürmer, S.; Winter, B. Photoelectron Spectroscopy Meets Aqueous Solution: Studies from a Vacuum Liquid Microjet. J. Phys. Chem. Lett. 2011, 2 (6), 633-641.

(46) Roy, K.; Artiglia, L.; van Bokhoven, J. A. Ambient Pressure Photoelectron Spectroscopy: Opportunities in Catalysis from Solids to Liquids and Introducing Time Resolution. ChemCatChem 2018, 10 (4), 666-682.

(47) Baer, M. D.; Tobias, D. J.; Mundy, C. J. Investigation of Interfacial and Bulk Dissociation of $\mathrm{HBr}, \mathrm{HCl}$, and $\mathrm{HNO} 3$ Using Density Functional Theory-Based Molecular Dynamics Simulations. J. Phys. Chem. C 2014, 118 (50), 29412-29420.

(48) Lewis, T.; Winter, B.; Thürmer, S.; Seidel, R.; Stephansen, A. B.; Freites, J. A.; Tobias, D. J.; Hemminger, J. C. Molecular Arrangement of a Mixture of Organosulfur Surfactants at the Aqueous Solution-Vapor Interface Studied by Photoelectron Intensity and Angular Distribution Measurements and Molecular Dynamics Simulations. J. Phys. Chem. C 2019, 123 (13), 8160-8170.

(49) Herrera, L.; Fan, C.; Do, D. D.; Nicholson, D. A revisit to the Gibbs dividing surfaces and helium adsorption. Adsorption 2011, 17 (6), 955-965.

(50) Netz, R. R.; Horinek, D. Progress in Modeling of Ion Effects at the Vapor/Water Interface. Annu. Rev. Phys. Chem. 2012, 63 (1), 401-418.

(51) Willard, A. P.; Chandler, D. Instantaneous Liquid Interfaces. J. Phys. Chem. B 2010, 114 (5), 1954-1958.

(52) Vazdar, M.; Pluhařová, E.; Mason, P. E.; Vácha, R.; Jungwirth, $P$. Ions at hydrophobic aqueous interfaces: Molecular dynamics with effective polarization. J. Phys. Chem. Lett. 2012, 3, 2087.

(53) Vrbka, L.; Mucha, M.; Minofar, B.; Jungwirth, P.; Brown, E. C.; Tobias, D. J. Propensity of soft ions for the air/water interface. Curr. Opin. Colloid Interface Sci. 2004, 9 (1), 67-73.

(54) Heeb, M. B.; Criquet, J.; Zimmermann-Steffens, S. G.; von Gunten, U. Oxidative treatment of bromide-containing waters: Formation of bromine and its reactions with inorganic and organic compounds - A critical review. Water Res. 2014, 48, 15-42.

(55) Clifford, D.; Donaldson, D. J. Direct Experimental Evidence for a Heterogeneous Reaction of Ozone with Bromide at the Air-Aqueous Interface. J. Phys. Chem. A 2007, 111 (39), 9809-9814.

(56) Moreno, C.; Baeza-Romero, M. T. A kinetic model for ozone uptake by solutions and aqueous particles containing I- and $\mathrm{Br}$-, including seawater and sea-salt aerosol. Phys. Chem. Chem. Phys. 2019, 21 (36), 19835-19856. 